Systematic Review

\title{
Sacroiliac Joint Fusion Methodology - Minimally Invasive Compared to Screw-Type Surgeries: A Systematic Review and Meta-Analysis
}

Zung Vu Tran, PhD, Anna Ivashchenko, MPH, and Logan Brooks, BA

From: MedAware Systems, Inc., Broomfield, $\mathrm{CO}$

Address Correspondence: Zung Vu Tran, PhD MedAware Systems, Inc. 3400 Industrial Lane, Suite $1 B$ Broomfield, CO 80020 E-mail: zvtran@medawaresystems.com

Disclaimer: See Pages 39-40. Conflict of interest: Each author certifies that he or she, or a member of his or her immediate family, has no commercial association (i.e., consultancies, stock ownership, equity interest, patent/licensing arrangements, etc.) that might pose a conflict of interest in connection with the submitted manuscript.

Manuscript received: 04-13-2017

Revised manuscript received: 04-25-2018

Accepted for publication: 06-12-2018

Free full manuscript: www.pain physicianjournal.
Background: Sacroiliac (SI) joint fusion represents a unique area of orthopedic surgery with procedural literature dating to the early 1920s, showing limited innovation in either technique or hardware over the last 90 years. Recent improvements in the diagnosis and treatment of SI joint dysfunction warrant comparisons to older surgical techniques.

Objective: To evaluate treatment efficacies and patient outcomes associated with minimally invasive joint fusion in comparison to screw-type surgeries.

Study Design: Systematic review and meta-analysis.

Setting: Electronic databases, EMBASE, Pubmed (Medline), manual bibliography cross-referencing for published works until Dec. 31, 2017.

Methods: A thorough literature search was performed in adherence to the Preferred Reporting Items for Systematic Reviews and Meta-Analyses (PRISMA) methodology. Data repositories accessed included Pubmed and EMBASE, until Dec. 31, 2017. All studies evaluating sacroiliac joint fusion and reporting quantifiable outcome data were included. Exclusion criteria included nonhuman studies, qualitative reviews, and meta-analyses. Data compilation, coding, and extraction were performed using MedAware Systems proprietary software. Data from each study were extracted by 2 analysts, using software that allowed automatic comparisons of all data fields. The standardized mean difference (SMD) was used as a summary statistic for pooling outcomes data across studies. Multiple outcome measures were grouped into 3 categories, according to similarity of measurements - Pain, Disability/Physical Function, and Global/QOL.

Results: A total of 20 studies had adequate data to calculate a SMD, and were included in the meta-analysis. Results of iFuse trials were compared to screw type trials, pooled in 3 categories of outcomes - Pain, Disability/Physical Function, and Global/QOL. The Pain category showed a statistically significant $(P=0.03)$ difference in outcomes for patients receiving the iFuse implant compared to screw types ( $\mathrm{SMD}=2.04$ [95\% Cl: 1.76 to 2.33 ] vs. 1.28 [95\% Cl: 0.47 to 2.09]), with ifuse showing significantly better outcomes. The Disability category also showed a statistically significant $(P=0.01)$ difference in outcomes for patients receiving the iFuse implant compared to screw types (SMD = 1.68 [95\% Cl: 1.43 to 1.94 ] vs. 0.26 [95\% Cl: -1.90 to 2.41$]$ ), with ifuse showing significantly better outcomes. For Global/Quality of Life (QOL) outcomes, there was a significant difference $(P=0.04)$ between iFuse and screw-type procedures (SMD $=0.99[95 \% \mathrm{Cl}: 0.75$ to 1.24$]$ vs. $0.60[95 \% \mathrm{Cl}$ : 0.33 to 0.88$]$ ), with iFuse showing significantly better outcomes. There was a statistically significant correlation between lower baseline Oswestry Disability Index (ODI) and Short Form 36 Health Survey (SF-36) values and better post treatment outcomes $(r 2=0.47, P<0.01$, and $r 2=0.30, P<0.01$, respectively). An association was found between pain at baseline and better outcomes $(r 2=0.21, P$ $<0.01$ ), where worse baseline pain was associated with better outcomes.

Limitations: There was a limited number of studies in this meta-analysis with treatments that could be properly classified as screw-type.

Conclusion: In this analysis, compared to screw-type surgeries, the iFuse system showed statistically superior outcomes. This was the case when outcome measures were classified into 3 main categories - Pain, Disability/Physical Function, and Global/QOL.

Key words: Meta-analysis, systematic review, sacroiliac joint, sacroiliac joint fusion

Pain Physician 2019: 22:29-40 
( acroiliac joint (SI) dysfunction is characterized by pain originating in the SI joint. Due to better understanding and differential diagnostic techniques, it has appreciated increasing interest as a source of low back pain. The causes of SI joint dysfunction are varied but include cases of trauma, arthritis, osteoarthritis/joint degeneration, pregnancy/delivery, as well as a complication of lumbar fusion (1-4). The prevalence of SI joint pathology has been difficult to accurately evaluate due to differing diagnostic techniques and criteria. The prevalence of SI joint pathology seems to range between $10 \%-62 \%$ with variation depending on study population. Of further importance is the high false-positive rate, at approximately $20 \%$ (4-6). This estimate, along with a National Health Interview Survey (NHIS, 2002) that reported lower back pain in $26.4 \%$ of responders (7), should indicate that $\mathrm{SI}$ joint dysfunction is a significant source of chronic pain and poses a prominent public health issue (8).

Conventional non-surgical therapies such as oral analgesic use, physical therapy, chiropractic treatment, radiofrequency denervation, and direct SI joint injections have been relied on as frontline therapies. However, they have shown limited durability in therapeutic benefit (9-11). The emerging disconnect between the growing incidence of diagnosed SI pathology and underwhelming treatment efficacy of medical treatment has been matched with an increase in surgical SI joint fusion procedures for intractable SI joint pain. Rather than managing inflammation and pain, surgical fusion of the SI joint immobilizes the joint and eliminates the motion thought to cause inflammation and SI joint pain (12).

The open surgical fusion of the $\mathrm{SI}$ joint has been reported in medical literature since the early 1920s (13-17). The invasive nature of the procedure reliably translates to poor clinical outcomes, long recovery times, and numerous surgical complications. Due to these procedural issues, open fusion was not widely adopted for the treatment of SI joint dysfunction. In the late 1980s, new techniques for SI fusion appeared, utilizing an open surgical approach in conjunction with screws and plates to assist in the joint fusion. These screw-type procedures were the first to be successfully used for the treatment of SI joint dysfunction (18-21). They have been widely adopted despite associated clinical complications and mixed outcomes. In one retrospective study (22) of screw type joint fusion nearly
$30 \%$ of study participants reported poor results or no effect from the surgery.

Revised surgical techniques of the past 2 decades succeeded in introducing novel approaches to SI fusion, but withheld any substantial improvement on existing hardware. Starting in 2008, new minimally invasive (MIS) fusion techniques began to gain traction. One advance has been the ifuse Implant System (SI Bone). The iFuse Implant System utilizes a percutaneous surgical approach to place several porous, triangular titanium implants to stabilize the joint and to facilitate fusion without the need for bone grafting (23). The ifuse system (SI Bone) has demonstrated pain reduction and improved quality of life (QOL) after treatment (24).

Despite SI joint fusion (SIJF) having a robust clinical history, no clear guidelines exist to support an optimal technique for SIJF. To date, systematic reviews and meta-analyses of this subject have included only a limited numbers of papers and offered no comparative analyses. The aim of this systematic review and meta-analysis was to evaluate all available literature in the domain of SIJF and to assess and compare the clinical efficacy of multiple surgical techniques.

\section{Related Reviews and Meta-Analyses}

In their recent paper, Heiney et al (25) included 18 studies that looked at procedure time, estimated blood loss, and hospital length of stay associated with surgical SIJF. The authors concluded that, true to its minimally invasive characteristics, there was minimal blood loss, short operating room times, and improvements in patient reported SI joint pain, disability, and quality of life scores.

Zaidi et al (26) included 16 studies in their systematic review of the literature. There was no quantitative component to this study, i.e., no meta-analysis or pooling of data. The authors concluded that, "surgical intervention for SI joint pain is beneficial in a subset of patients. However, serious consideration of the cause of pain and alternative treatments should be given before performing the operation."

Finally, in a more recent paper, Lingutia et al (27) included 6 studies to "determine whether SIJF for LBP [low back pain] is effective in reducing pain when the $S I J$ is known to be the pain generator." Outcome measures examined were VAS pain, ODI, SF-36 PCS/ MCS and Majeed score. They concluded that, "SIJF appears to be a satisfactory procedure for alleviating pelvic girdle pain (27)." 


\section{Methods}

We followed the Preferred Reporting Items for Systematic Reviews and Meta-Analyses (PRISMA) guidelines (28).

\section{Search Strategy}

A series of search queries were deployed to target publications addressing $\mathrm{SI}$ joint dysfunction and joint fusion methodologies. Search strings were constructed using US National Library of Medicine's Medical Subject Headings (MeSH) terms (human, sacroiliac joint fusion, clinical trial, etc.), Boolean operators ("and," "not," "or"), and syntax appropriate to the search interface. Various combinations of publication type, patient criteria, intervention, comparison to other treatment, and patient outcomes of known interest (Table 1) were used to build a custom set of search strings satisfying preliminary study criteria.

\section{Data Sources}

Studies were retrieved via computerized literature searches of electronic databases (PubMed, EMBASE) and cross-referencing from retrieved articles. Initial broad EMBASE search queries were supplemented with focused PubMed searches.

\section{Other Resources, Checks of Completeness}

Cross-referencing of selected bibliographies against paper accumulated during the electronic search phase comprised the manual step of ensuring that all pivotal studies have been included. Study selection criteria included:

1) interventional

2) human subject publications

3) reported patient outcomes.

No publication date range exclusion was applied.

\section{Participants}

Participant criteria targeted SI-associated pathology such as 1) SI joint dysfunction, 2) SIJF, 3) SI joint disruption, 4) sacroiliitis, 5) pregnancy, 6) trauma.

\section{Interventions}

Interventions of interest included 1) medical management and 2) surgical management of the SI joint.

\section{Outcomes}

Primary outcomes were limited to pain, disability/ physical function, and QOL measures. These variables, associated with long-term convalescence, were found to be most commonly reported in SIJF literature.

\section{Data Collection and Analysis}

\section{Selection of Studies}

The study selection process is outlined in standard PRISMA (29) flowchart (Fig. 1). Treatment groups and outcome measures utilized in published literature were identified. All publications were classified by type of experimental design and patient diagnosis.

\section{Data extraction}

All retrieved publications were coded. The major categories of coded variables included

1) journal-level information,

2) study characteristics,

3) subject characteristics,

4) SI joint conditions,

5) SI joint treatments,

6) fusion methodology,

7) primary outcomes, and

8) complications.

Table 1. Patient, intervention, outcome, and publication search criteria applied to identification and selection of clinical research for analysis.

\begin{tabular}{|c|c|}
\hline \multirow[t]{5}{*}{ Patient } & Human \\
\hline & $\begin{array}{l}\text { Sacroiliac joint dysfunction, fusion, } \\
\text { disruption }\end{array}$ \\
\hline & Sacroiliitis \\
\hline & Pregnancy \\
\hline & Trauma \\
\hline \multirow{8}{*}{$\begin{array}{l}\text { Intervention, Comparison, } \\
\text { Control }\end{array}$} & Medical management \\
\hline & Minimally invasive SI joint fusion \\
\hline & Open SI joint fusion \\
\hline & Iliosacral screw \\
\hline & Single iliac screw \\
\hline & Double iliac screw \\
\hline & Sacroiliac fusion \\
\hline & iFuse Implant System \\
\hline \multirow[t]{4}{*}{ Outcome } & Disability \\
\hline & Pain \\
\hline & Quality of life \\
\hline & Patient satisfaction \\
\hline \multirow[t]{4}{*}{ Publication } & Human \\
\hline & Prospective \\
\hline & Retrospective \\
\hline & Randomized \\
\hline
\end{tabular}


MedAware Systems, Inc. has developed a process by which this data extraction process is nearly $100 \%$ accurate. It is a patent-pending process (Systems and Methods for Biomedical Research Database Development and Uses Thereof.

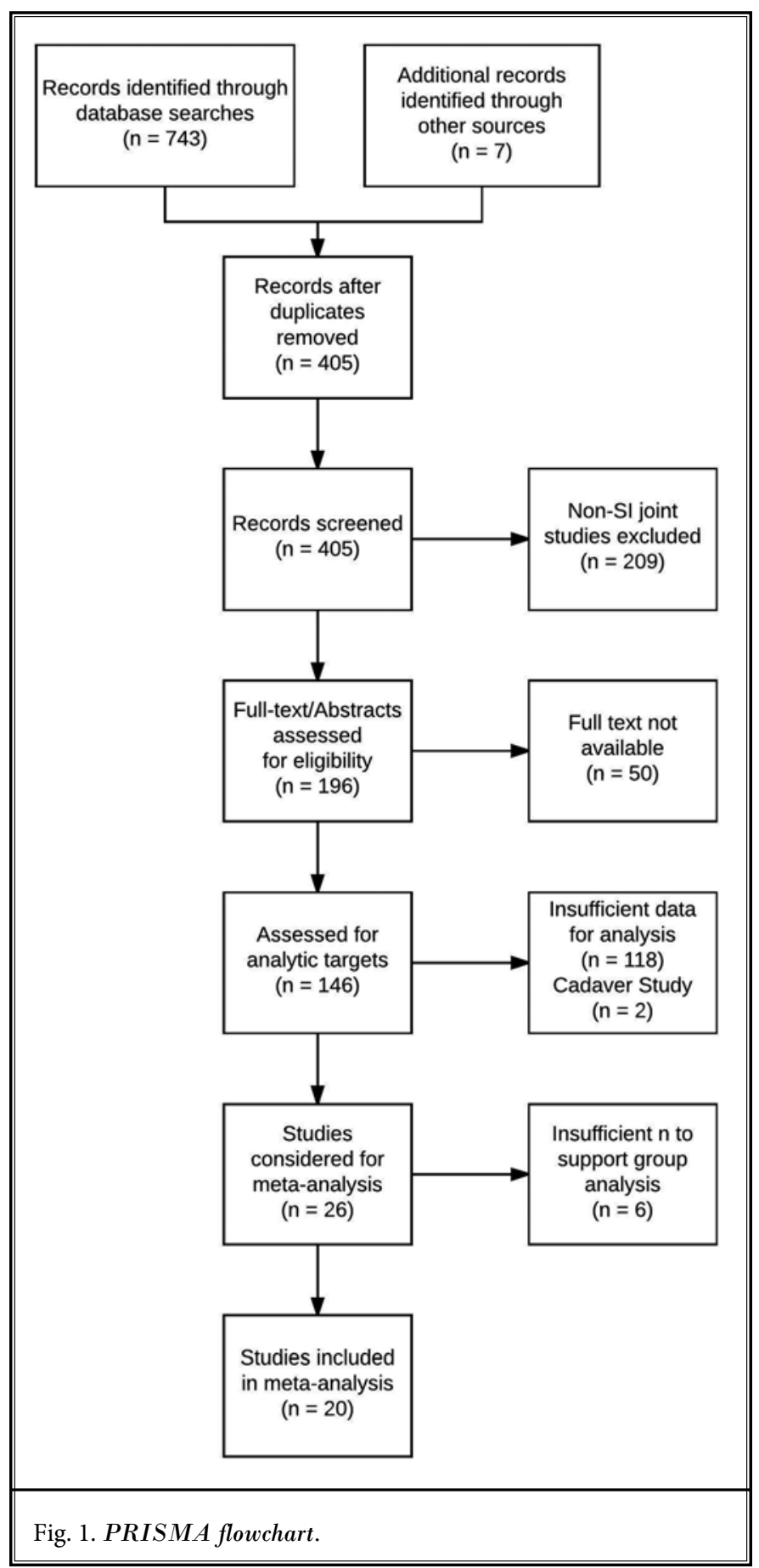

\#PCT/ US15/ 15858) where 2 analysts, blinded to each other, extract data from the same study. The proprietary software compares each data field for matches (or mismatches). When there is a mismatch, a senior analyst reviews the data in question and reconciles the data. This process provides a near $100 \%$ level of accuracy for data capture.

\section{Measures of Treatment Effect}

The standardized mean difference (SMD) (30), a variation of the MedAware Standardized Index (MSI), a patent-pending estimate of treatment efficacy, was used as a summary statistic for pooling data across studies and outcome measures. In a meta-analytic context, when studies assess similar outcomes (constructs) but measure them in a variety of ways (for example, all studies measuring pain but using different psychometric scales), it is necessary to standardize the results of the studies to a uniform scale before they can be combined. The SMD expresses the size of the intervention effect in each study relative to the variability observed in that study. The "unit" of the SMD is a standard deviation, with a positive SMD showing better efficacy, while a negative SMD shows a worse efficacy (30-34).

After data coding and extraction, studies were excluded from analysis if data were insufficient to calculate a SMD - that is, the results of a study had to include an outcome measure (e.g., Pain Visual Analogue Scale value between 0 and 10) with baseline and post-surgery values, along with a measure of variance such as the standard deviation.

\section{Synthesis}

\section{Subgroup Analysis}

Surgical SI joint interventions were limited to 10 groupings for comparison of treatment effect sizes. The groups encompassed treatments that were most commonly reported in the literature.

Surgical SI fusion interventions identified for analysis included:
1) Control/SOC
2) Screw-Type Fusion
3) Open Fusion
4) iFuse Implant (SI-Bone)
5) Other Minimally Invasive Fusion
6) Other surgical procedure. 
Nonsurgical treatments included:

7) Medical/Nonoperative

8) Physical Therapy

9) Nerve Block/Neurotomy

10) Steroid injection.

Of these, 2 groups - 2) Screw-Type Fusion and 4) iFuse Implant (SI-Bone) - contributed sufficient data to permit analysis.

Numerous outcome measures were used to capture the effects of surgery in terms of patient outcomes. Only the measures of treatment effect and patient wellbeing were found to be used consistently across all treatment groups in all screened studies. To facilitate analysis, the following 3 primary outcome groupings were defined:

1. Pain. The Pain outcome category included the "Pain VAS," "Visual Analog Scale (VAS) - Pain," "Pain Numeric Rating Scale (NRS)," "Short Form 12 Health Survey (SF-12) - Bodily Pain"

2. Disability/Physical Function. The Disability/Physical Function outcome category included the "Oswestry Disability Index (ODI)," "Pain Disability Index (PDI)," "Roland and Morris Disability Questionnaire (RMDQ)," "Short Form 12 Health Survey (SF-12) Physical Composite Score," "Short Form 36 Health Survey (SF-36) - Physical Component Summary," "Short Form 36 Health Survey (SF-36) - Physical Functioning"

3. Global/Quality of Life (QOL). The Global/QOL outcome category included the "Short Form 12 Health Survey (SF-12) - Mental Composite Score," "Short Form 36 Health Survey (SF-36) - General Health Perceptions," "Short Form 12 Health Survey (SF12) - Mental Component Summary," "Short Form 36 Health Survey (SF-36) - Mental Health," "Short Form 36 Health Survey (SF-36) - Role Limitations due to Emotional Problems," "Short Form 36 Health Survey (SF-36) - Social Functioning," "Short Form 36 Health Survey (SF-36) - Vitality," "Short Form Health Survey 36-Item (SF-36) - General Health," "EuroQol (EQ-5D) - Time Trade Off," "Euroqol- 5D (EQ-5D)," "European Quality of Life Questionnaire (EQ- 5D) Visual Analog Scale," "Patient Satisfaction"

\section{Data Analysis}

Pairwise subgroup comparisons were accomplished using Student's t-test under the normality assumption and pooled sample variance. Normality was verified with QQ Plots; sample data distributions were visualized with histograms.

\section{Results}

A total of 405 citations were screened for SI joint intervention (Fig. 1). Twenty studies had adequate data to calculate a SMD and were included in the meta-analysis (Table 2) (35-51). Of those, 14 publications evaluated the ifuse procedure. Results of the iFuse trials ( $n$ $=14)$ were compared to screw-type trials $(n=6)$ in 3 categories of outcomes: Pain, Disability/Physical Function, and Global/QOL.

\section{Systematic Literature Review: Study Characteristics}

Sample size ranged from 10 to 172 in the ifuse group, with a median sample size of 60 . The screw-type group had a median sample size of 20, ranging from 6 to 149. All participants were adults between the ages of 43.2 and 64 years. Both treatment groups were comprised primarily of females (iFuse $71.6 \%$ vs Screw Type $78.1 \%$ ) (Table 2). Results were informally evaluated for homogeneity of effect size estimates (Fig. 2). The funnel plot of study sample sizes against corresponding estimates of effect size reveals the greatest variability in effect size estimates across studies of low sample size, as expected.

There were 4 randomized clinical trials (RCTs) investigating the iFuse implant system. Of these, none included a placebo or a sham treatment group. There were no randomized trials investigating the effects of screw-type procedures. The duration of subjects' post treatment follow-up was found to range from 2 weeks to over 3 years, with no studies reporting outcome measurements within meaningfully coincident timeframes.

\section{Meta-Analysis: Primary Interventional Effects}

Fourteen publications reported an iFuse implant treatment group. Based on the individually reported subject baseline and postoperative measurements across all categories of patient outcome, the cumulative effect sizes ranged from 1.22 to 4.15 , with an average pooled effect size of $1.64(\mathrm{SD}=0.95,95 \% \mathrm{Cl}=[1.48$, 1.81]) in this treatment category (Table 3A). These results were evaluated using the GRADE scale. Due to few RCTs, possible publication bias, and heterogeneity in outcome, the evidence was rated as poor (GRADE $=1$ ).

Seven publications reported a screw type treatment group. Based on the individually reported subject baseline and postoperative measurements across all categories of patient outcome, the cumulative effect sizes ranged from 0.38 to 4.19 , with an average pooled effect size of $0.72(S D=1.55,95 \% \mathrm{Cl}=[0.21,1.23])$ in this 
Table 2. Study Demographics. (NR + not reported).

\begin{tabular}{|c|c|c|c|c|c|}
\hline Author & Publication Year & Treatment Group & Age & $\%$ Female & Sample Size \\
\hline Buchowski (20) & 2005 & Screw Type & 45.1 & 85 & 20 \\
\hline Copay (43) & 2015 & iFuse & NR & NR & 77.5 \\
\hline Cummings (37) & 2013 & iFuse & 64 & 67 & 18 \\
\hline Duhon (39) & 2013 & iFuse & 50.2 & 66 & 32 \\
\hline Duhon (44) & 2016 & iFuse & 50.9 & 69.8 & 172 \\
\hline Gaetani (38) & 2013 & iFuse & 53.2 & 100 & 10 \\
\hline Kancherila (50) & 2017 & iFuse & 52.7 & 68.9 & 45 \\
\hline Khurana (35) & 2009 & Screw Type & 48.7 & 73.3 & 15 \\
\hline Halki (47) & 2010 & Screw Type & NR & NR & 10 \\
\hline Mason (36) & 2013 & Screw Type & 56.95 & 83.6 & 55 \\
\hline Papanastassiou (49) & 2011 & Screw Type & 58.8 & 50 & 6 \\
\hline Polly (48) & 2015 & iFuse & 50.2 & 73.5 & 102 \\
\hline Polly (46) & 2016 & iFuse & 50.2 & 60.9 & 102 \\
\hline Rudolf (41) & 2014 & iFuse & 58 & 77 & 21 \\
\hline Schutz (22) & 2006 & Screw Type & 43.2 & 70.5 & 17 \\
\hline Sachs (40) & 2014 & iFuse & 57.7 & 71 & 144 \\
\hline Sachs (51) & 2016 & iFuse & 57.5 & NR & 107 \\
\hline Smith (23) & 2013 & iFuse & 57.4 & 71.9 & 114 \\
\hline Smith (23) & 2013 & Screw Type & 45.8 & 69.1 & 149 \\
\hline Sturesson (45) & 2016 & iFuse & 49.4 & 73.1 & 52 \\
\hline Whang (42) & 2006 & iFuse & 50.2 & 73.5 & 102 \\
\hline
\end{tabular}

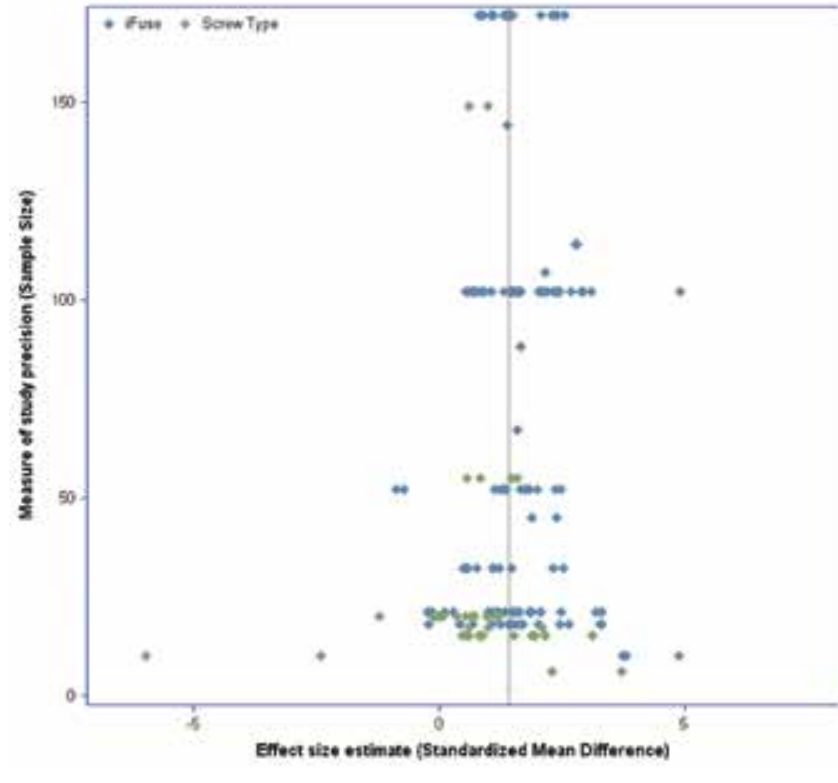

Fig. 2. Funnel plot to test the effects for publication bias. The symmetry of the funnel plot suggests no systematic heterogeneity. treatment category (Table 3B). Due to a lack of randomized controlled trials and heterogeneity in outcome, these results were rated as very poor quality $(G R A D E=0)$.

The cumulative pooled effect size across all outcome categories showed a statistically significant $(P<0.0001)$ difference favoring patients who received the ifuse implant compared to screw-type $(\mathrm{SMD}=1.64,95 \% \mathrm{Cl}=$ [1.48 to 1.81$]$ vs. SMD $=0.72,95 \% \mathrm{Cl}=[0.21$ to 1.23]) (Fig. 3A). Treatment effects across outcome categories are summarized in Table 4.

The Pain category showed a statistically significant $(P=0.03)$ difference in outcomes for patients receiving the ifuse implant compared to screw-type $(\mathrm{SMD}=2.05,95 \% \mathrm{Cl}=$ [1.78 to 2.32 ] vs. $1.28,95 \% \mathrm{Cl}=[0.47$ to 2.09$]$ ), with iFuse showing significantly better outcomes (Fig. 3B). The Disability category also showed a statistically significant $(P=0.01)$ difference in outcomes for patients receiving the iFuse implant compared to screw types (SMD 
Sacroiliac Joint Fusion-iFuse Implant System vs. Screw-type Surgeries

Table 3A. List of studies evaluating the iFuse system that are included in the meta-analysis.

\begin{tabular}{|l|c|c|c|c|c||}
\hline \multicolumn{1}{|c}{ SI Fusion Modality: iFuse } & \multicolumn{3}{c||}{ Effect } \\
\hline Study & Publication Year & Study Design & (SMD) & (SD) & 95\% CI \\
\hline Cummings (43) & 2015 & Prospective Clinical & 1.63 & $(0.04)$ & $(1.27,1.99)$ \\
\hline Duhon (39) & 2013 & Retrospective Case Study & 1.64 & $(0.96)$ & $(1.13,2.15)$ \\
\hline Duhon (44) & 2013 & Prospective Cohort & 1.22 & $(0.72)$ & $(0.71,1.73)$ \\
\hline Gaetani (38) & 2016 & Prospective Clinical & 1.54 & $(0.60)$ & $(1.26,1.82)$ \\
\hline Kancherla (50) & 2013 & Chart Review & 4.15 & $(0.64)$ & $(2.56,5.75)$ \\
\hline Polly (48) & 2017 & Retrospective Cohort & 2.14 & $(0.35)$ & $(1.00,5.29)$ \\
\hline Polly (46) & 2015 & Prospective Randomized & 1.56 & $(1.18)$ & $(0.81,2.31)$ \\
\hline Rudolf (41) & 2016 & Prospective Randomized & 2.07 & $(0.70)$ & $(1.49,2.65)$ \\
\hline Sachs (40) & 2014 & Retrospective Cohort & 1.41 & $(0.98)$ & $(0.94,1.89)$ \\
\hline Sachs (51) & 2014 & Prospective Cohort & 1.38 & NR & - \\
\hline Smith (23) & 2016 & Retrospective Cohort & 2.17 & NR & - \\
\hline Sturesson (45) & 2013 & Retrospective Cohort & 2.80 & $(0.03)$ & $(2.55,3.04)$ \\
\hline Whang (42) & 2016 & Prospective Randomized & 1.34 & $(1.03)$ & $(0.72,1.96)$ \\
\hline \multicolumn{2}{|c|}{2006} & Prospective Randomized & 1.72 & $(0.74)$ & $(1.34,2.11)$ \\
\hline
\end{tabular}

Table 3B. List of studies evaluating screw type fusion that are included in the meta-analysis.

\begin{tabular}{|l|c|c|c|c|c|}
\hline \multicolumn{3}{|c|}{ SI Fusion Modality: Screw Type } & \multicolumn{3}{c|}{ Effect } \\
\hline \multicolumn{1}{|c|}{ Study } & Publication Year & Study Design & (SMD) & (SD) & 95\% CI \\
\hline Buchowski (20) & 2005 & Consecutive Case Series & 0.38 & $(0.63)$ & $(0.03,0.73)$ \\
\hline Khurana (35) & 2009 & Chart Review & 1.41 & $(0.88)$ & $(0.78,2.04)$ \\
\hline Halki (47) & 2010 & Prospective Cohort & 4.19 & $(2.51)$ & $(26.71,18.34)$ \\
\hline Mason (36) & 2013 & Retrospective Cohort & 1.13 & $(0.50)$ & $(0.33,1.92)$ \\
\hline Papanastassiou (49) & 2011 & Retrospective Case Study & 3.02 & $(0.99)$ & $(5.91,11.95)$ \\
\hline Schutz (22) & 2006 & Retrospective Case Study & 1.24 & $(0.78)$ & $(0.69,3.17)$ \\
\hline Smith (23) & 2013 & Retrospective Cohort & 0.80 & $(0.27)$ & $(1.63,3.24)$ \\
\hline \multicolumn{2}{|c|}{ Cumulative SMD: (GRADE=0) } & 0.72 & $(1.55)$ & $(0.21,1.23)$ \\
\hline
\end{tabular}

$=1.68,95 \% \mathrm{Cl}=[1.43$ to 1.94$]$ vs. $0.26,95 \% \mathrm{Cl}=[-1.90$ to 2.41$])$, with iFuse showing significantly better outcomes. For Global/QOL outcomes, there was a significant difference $(P=0.04)$ between iFuse and screw-type procedures as well (SMD $=0.99,95 \% \mathrm{Cl}=[0.75$ to 1.24$]$ vs. $0.60,95 \% \mathrm{Cl}=[0.33$ to 0.88$])$, with iFuse showing significantly betteroutcomes (Table 4).

\section{Baseline Patient Characteristics Correlation to Treatment Outcome}

There was a statistically significant correlation between lower baseline Oswestry Disability Index (ODI) values and better outcomes $\left(r^{2}=0.47, P<0.01\right)$ (Fig. 4A). A similar relationship was present between higher baseline Short Form 36 Health Survey (SF-36) and bet- ter outcomes $\left(r^{2}=0.30, P<0.01\right)$ (Fig. 4B). An inverse relationship was found between worse pain at baseline and better outcomes $\left(r^{2}=0.21, P<0.01\right)$. (Fig. 4C).

\section{Methodological Quality Assessment}

Methodological quality assessment was performed using the GRADE criteria (52). The GRADE scale assigns a score from 0 to 4 to rate the cumulative quality of the evidence across a set of studies, with 0 denoting very low quality and 4 denoting very high quality. Overall, the quality of the SI fusion evidence was scored low to very low, primarily due to the lack of RCTs and the heterogeneity of publications.

There was no RCT evidence examining screw-type procedures, and a significant body of literature was 
Table 4. Summary and comparison of treatment effects across outcome category.

\begin{tabular}{|c|c|c|c|c|c|c|}
\hline \multirow{2}{*}{ Outcome Group } & \multirow{2}{*}{ Treatment Group } & \multicolumn{3}{|c|}{ Effect } & \multirow{2}{*}{$\begin{array}{c}\text { Significance } \\
\text { ( } P \text { value })\end{array}$} & \multirow{2}{*}{ GRADE } \\
\hline & & (SMD) & (SD) & $95 \%$ CI & & \\
\hline \multirow{2}{*}{ Pain } & iFuse & 2.05 & $(0.97)$ & $(1.77,2.32)$ & \multirow{2}{*}{0.026} & 1 \\
\hline & Screw Type & 1.28 & $(1.21)$ & $(0.47,2.09)$ & & 0 \\
\hline \multirow{2}{*}{ Disability/Physical Function } & iFuse & 1.68 & $(0.81)$ & $(1.43,1.94)$ & \multirow{2}{*}{0.007} & 1 \\
\hline & Screw Type & 0.26 & $(2.81)$ & $(-1.90,2.41)$ & & 0 \\
\hline \multirow{2}{*}{ Global, QOL } & iFuse & 0.99 & $(0.69)$ & $(0.75,1.24)$ & \multirow{2}{*}{0.044} & 1 \\
\hline & Screw Type & 0.60 & $(0.55)$ & $(0.33,0.88)$ & & 0 \\
\hline
\end{tabular}

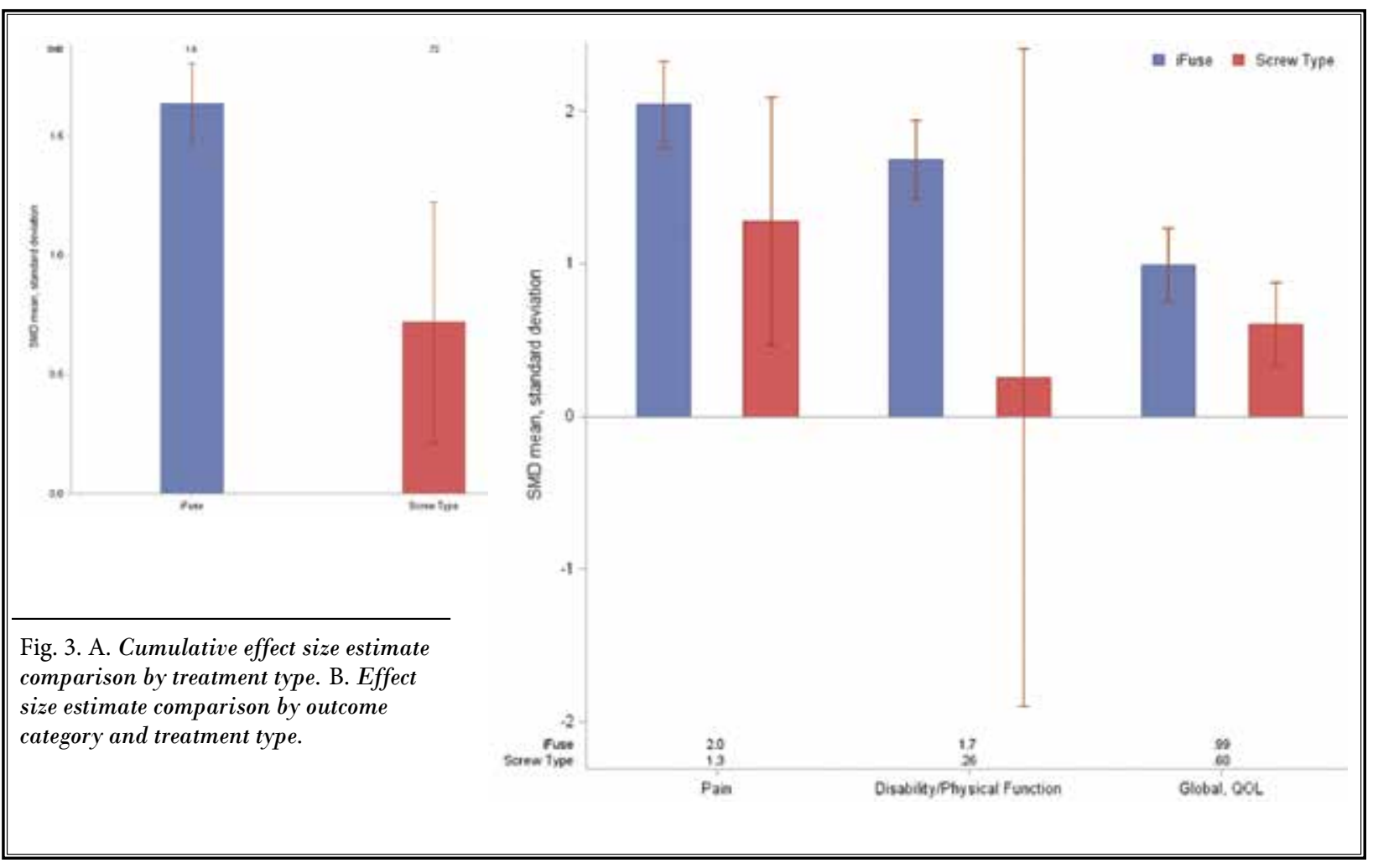

funded by SI-Bone, Inc., introducing potential publication bias.

The number of various outcomes evaluating Disability/Physical Function and Global/ QOL was large; however, most assessments were properly validated tools. Despite the overall low quality of evidence, this literature review and meta-analysis offers an important examination of the effects of surgical SI fusion techniques on pain, disability, and QOL, and illuminates the present gaps in surgical and pain literature.

\section{Discussion}

Although surgical SI fusion procedures have been available for a century, it was not until the late 1980s that clinical trials took aim at evaluating their efficacy in the treatment of SI joint pain and dysfunction. The apparent neglect of this area of research resulted in a limited body of literature available for informed comparisons of even the most prevalent techniques. What little data are available span decades in publication dates, employ a great variety of outcomes measures, 


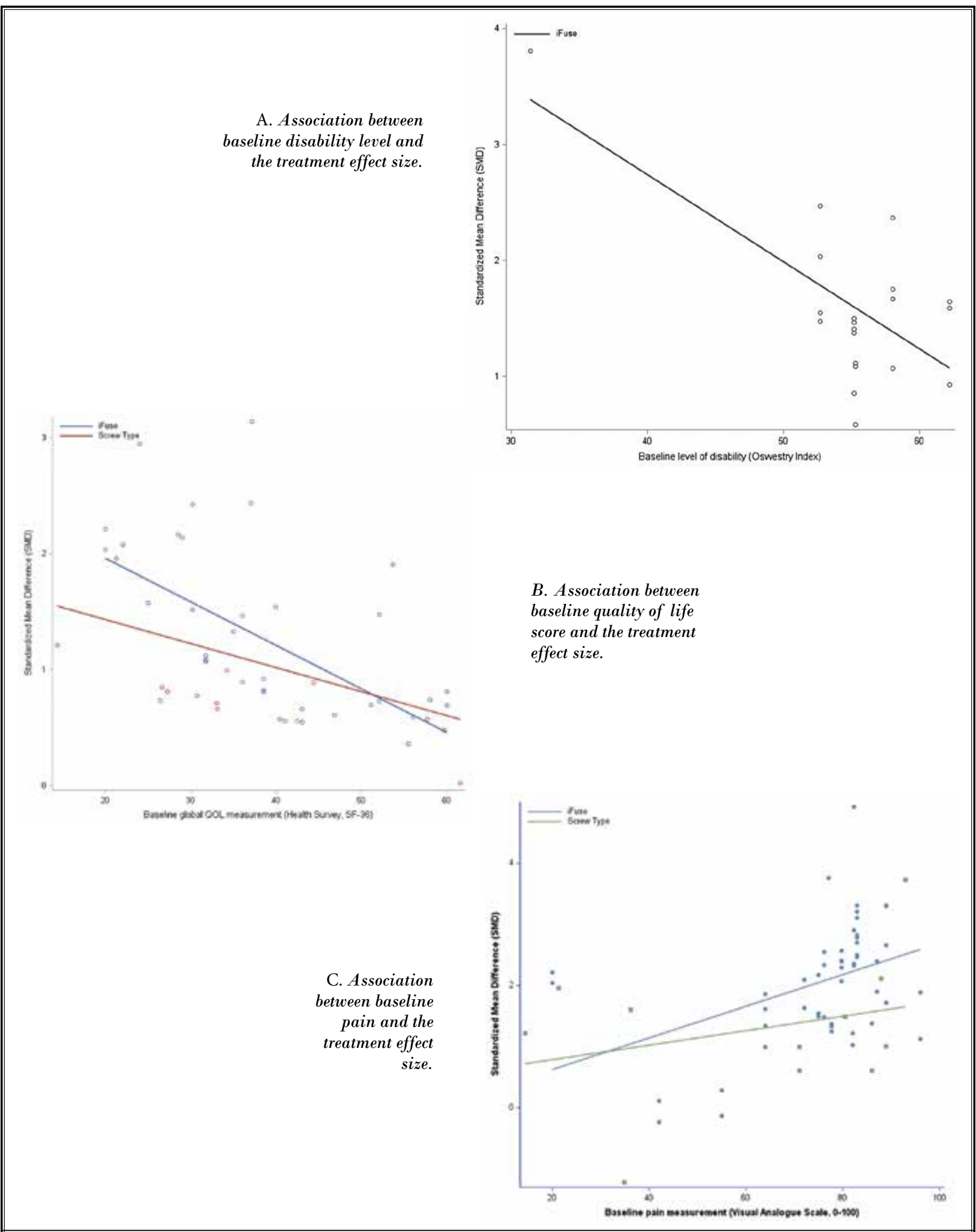

Fig. 4. Plot graphs showing the changes showing baseline and treatment effects. 
and adhere to no standard timeline for subject followup post-surgery.

SI Bone, Inc. emerged as a leading proponent of advancing clinical evidence in the field and, as a result, became over-represented in this research literature. Fourteen of the 20 studies included in this analysis used the ifuse technique. This imbalance likely represents both SI-Bone's dedication to publishing supporting evidence for the iFuse Implant system as well as a deficiency in the evaluation of other SIJF procedures. It may also have introduced a potential treatment bias into analysis.

Our meta-analysis showed that, overall, the ifuse technique, when compared to "screw-type" techniques, delivers significantly better outcomes in all 3 categories of outcomes - pain, disability, and QOL. A significant correlation was noted between baseline disability and pain levels with post-treatment outcomes, suggesting that patients with a high level of baseline pain and a low level of baseline disability may appreciate greater symptom reduction.

Further attention should be given to the evaluation of post-operative complications of both the ifuse technique, and the screw-type procedures. The need for this scrutiny is motivated by post-market surveillance findings in MedWatch, as well as a study examining post-operative complications related to ifuse, suggesting overall complication rates of $13.2 \%$ at 90 days and $16.4 \%$ at 6 months post-operatively (53).

Historically, screw-type procedures maintained higher complication rates (between 30\%-52\%); however, these studies had smaller sample sizes and minimal external validity $(18,20,54)$.

As noted, the lack of comparative data was a limitation for this meta-analysis. The observed scarcity of literature suggests an effort must be made to continue the conduct and publication of well-powered, randomized, controlled research investigating the effects of various SI treatment modalities on pain and long-term patient well-being. The overwhelming prevalence of single-arm trials, retrospective reviews, cohort studies, and case series in this area remains a major impediment to effective meta-analysis and informed clinical practice.

\section{Acknowledgments}

Funding for this research was provided by SIBone, the manufacturer of the iFuse system. SI-Bone did not participate in any aspect of the performance of this research, and had no role in the writing of this manuscript.

We wish to acknowledge the Medical Research Analysts (MRAs), employed by MedAware Systems, Inc., who participated in the data extraction process: Arnold Aguilar, Logan Greydanus, Elissa K. Hoitt, Laura O. James, Kate Yzquierdo, Krishna Kunapuli, Vanessa Nault, Kristin C. Nicotra, Nicholas Oreschnick, Galen Peterson, Travis E. Spear, and Reed M. Terrell.

Dr. Tran had full access to all the data in the study and takes responsibility for the integrity of the data and the accuracy of the data analysis. Dr. Tran and Ms. Ivashchenko designed the study protocol. Mr. Brooks managed the literature searches and summaries of previous related work and wrote the first draft of the manuscript. Dr. Tran provided revision for intellectual content and final approval of the manuscript.

Dr. Tran is a biostatistician, and a retired Professor of Biostatistics and Pediatrics.

Funding/Support: The authors wish to disclose and thank the sponsor of the study, SI-Bone. The study was conducted by the authors and other staff of MedAware Systems, Inc. The study was sponsored by SI-Bone. The sponsorship was limited to a contract between SI-Bone and MedAware Systems, Inc. to perform a systematic review and meta-analysis (this manuscript). SI-Bone had no influence or interference after the protocol was designed, and had no role in the writing of the manuscript.

Role of Sponsor: The financial sponsor of this work had no role in the design and conduct of the study or the collection, management, analysis, and interpretation of the data. The sponsor also did not have a role in the preparation or review of the manuscript or the decision to submit. The authors also wish to thank their team of medical research analysists for their assistance in preparation of this manuscript. We also would like to thank the editorial board of Pain Physician for review and criticism in improving the manuscript. 


\section{References}

1. Kibsgård TJ, Røise O, Stuge B. Pelvic joint fusion in patients with severe pelvic girdle pain - a prospective singlesubject research design study. BMC Musculoskelet Disord 2014; 15:85.

2. MJ DePalma. Etiology of chronic low back pain in patients having undergone lumbar fusion. Pain Med 2011; 12:732-739.

3. Bernard TN Jr, Kirkaldy-Willis WH. Recognizing specific characteristics of nonspecific low back pain. Clin Orthop Relat Res 1987; 217:266-280.

4. Cohen SP. Sacroiliac joint pain: A comprehensive review of anatomy, diagnosis, and treatment. Anesth Analg 2005; 101:1440-1453.

5. Sembrano JN, Polly DW Jr. How often is low back pain not coming from the back? Spine 2009; 34:E27-E32.

6. Simopoulos TT, Manchikanti L, Singh V. A systematic evaluation of prevalence and diagnostic accuracy of sacroiliac joint interventions. Pain Physician 2012; 15:E305-44.

7. Deyo RA, Mirza SK, Martin BI. Back pain prevalence and visit rates: Estimates from U.S. national surveys, Spine (Phila Pa 1976) 2006; 31:2724-2727.

8. Katz JN. Lumbar disc disorders and low-back pain: Socioeconomic factors and consequences.] Bone Joint Surg Am 2006; 88 Suppl 2:21-24.

9. Spiker WR, Lawrence BD, Raich AL, Skelly AC, Brodke DS. Surgical versus injection treatment for injection-confirmed chronic sacroiliac joint pain. Evid- Based Spine-Care J 2012; 3:41-53.

10. Lorio MP, Rashbaum R. ISASS Policy Statement - minimally invasive sacroiliac joint fusion. Int J Spine Surg 2014; 8:25.

11. Patel N. Twelve-month follow-up of a randomized trial assessing cooled radiofrequency denervation as a treatment for sacroiliac region pain. Pain Pract Off J World Inst Pain 2015; 16:154-167.

12. Moore MR. Diagnosis and surgical treatment of chronic painful sacroiliac dysfunction: The integrated function of the lumbar spine and sacroiliac joint. In: The Integrated Function of the Lumbar Spine and Sacroiliac Joint. ECO Rotterdam, San Diego, CA, USA, 1995: 339-345.

13. Smith-Petersen MN. Arthrodesis of the sacroiliac joint. A new method of approach. J Bone Joint Surg 1921;
3-A:400-405.

14. Smith-Petersen MN, Rogers WA. Endresult study of arthrodesis of the sacroiliac joint for arthritis-traumatic and non-traumatic. J Bone Joint Surg 1926; 8- A:118

15. Smith-Petersen MN, Rogers WA. Arthrodesis for tuberculosis of the sacroiliac joint. JAMA 1926; 86:26-30.

16. Gaenslen FJ. Sacro-iliac arthrodesis: Indications, author's technic and end- results. JAMA 1927; 89:5.

17. Campbell W. An operation for extraarticular fusion of the sacro-iliac joint. Surg, Gyn, Obs 1927; 45:218-219

18. Waisbrod H, Krainick JU, Gerbershagen HU. Sacroiliac joint arthrodesis for chronic lower back pain. Arch Orthop Trauma Surg 1987; 106:238--240.

19. Belanger TA, Dall BE. Sacroiliac arthrodesis using a posterior midline fascial splitting approach and pedicle screw instrumentation: A new technique. J Spinal Dis 2001; 14:118-124.

20. Buchowski JM, Kebaish KM, Sinkov V, Cohen DB, Sieber AN, Kostuik JP. Functional and radiographic outcome of sacroiliac arthrodesis for the disorders of the sacroiliac joint. Spine J 2005; 5:520-528.

21. Wise $C L$, Dall BE. Minimally invasive sacroiliac arthrodesis: Outcomes of a new technique. J Spinal Disord Tech 2008; 21:579-584.

22. Schutz U, Grob D. Poor outcome following bilateral sacroiliac joint fusion for degenerative sacroiliac joint syndrome. Acta Orthop Belg 2006; 72:296-308.

23. Smith AG, Capobianco R, Cher D, Rudolf L, Sachs D, Gundanna M, Shamie AN. Open versus minimally invasive sacroiliac joint fusion: A multi-center comparison of perioperative measures and clinical outcomes. Ann Surg Innov Res 2013; 7:14.

24. Stark JG, Abner Fuentes J, Fuentes TI, Idemmili $C$. The history of sacroiliac joint arthrodesis: A critical review and introduction of a new technique. Curr Orthop Pract 2011; 22:545-557.

25. Heiney J, Capobianco R, Cher D. A systematic review of minimally invasive sacroiliac joint fusion utilizing a lateral transarticular technique. International Journal of Spine Surgery, 2015; 9:40.

26. Zaidi HA, Montoure AJ, Dickman CA. Surgical and clinical efficacy of sacro- iliac joint fusion: A systematic review of the literature. J Neurosurg Spine 2015; 23:59-66.

27. Lingutla KK, Pollock R, Ahuja S. Sacroiliac joint fusion for low back pain: A systematic review and meta-analysis. Eur Spine ] 2016; 25:1924-1931

28. Moher D, Liberati A, Tetzlaff J, Altman DG, The PRISMA Group. Preferred Reporting Items for Systematic Reviews and Meta-Analyses: The PRISMA Statement. PLoS Med 2009; 6:e1000097.

29. Cochrane Handbook for Systematic Reviews of Interventions Version 5.1.0 [updated March 2011]. The Cochrane Collaboration, 2011. Available from www. handbook.cochrane.org.

30. Kelley GA, Tran ZV. Original metric vs. standardized effect sizes for meta analysis of clinical data. Prev Cardiol 2001; 4:40-45.

31. Tran ZV, Weltman A. Differential effects of exercise on serum lipid and lipoprotein levels seen with changes in body weight: A meta-analysis. JAMA 1985; 254:919-924 [PMID: 4021025]; translated, published in Japanese language edition, JAMA 254 (February):43-50.

32. Cohen J. Statistical power analysis for the behavioral sciences (2nd ed.). New Jersey: Lawrence Erlbaum; 1988; page . 66-70.

33. Glass GV. Primary, secondary and meta-analysis of research. Educational Researcher 1976; 10: 3-8.

34. Kelley GA, Tran ZV. Original metric vs. standardized effect sizes for meta- analysis of clinical data. Preventive Cardiology Winter 2001; 4:40-45. [PMID: 11828198]

35. Khurana A, Guha AR, Mohanty K, Ahuja S. Percutaneous fusion of the sacroiliac joint with hollow modular anchorage screws: Clinical and radiological outcome. J Bone Joint Surg $\mathrm{Br}$ 2009; 91:627-631.

36. Mason LW, Chopra I, Mohanty K. The percutaneous stabilisation of the sacroiliac joint with hollow modular anchorage screws: A prospective outcome study. Eur Spine ] 2013; 22:2325-2331.

37. Cummings J, Capobianco RA. Minimally invasive sacroiliac joint fusion: One-year outcomes in 18 patients. Ann Surg Innov Res 2013; 7:12.

38. Gaetani P, Miotti D, Risso A, Bettaglio R, Custodi V, Silvani V. Percutaneous arthrodesis of sacro-iliac joint: a pilot study. J Neurosurg Sci 2013; 57:297-301. 
39. Duhon BS, Cher DJ, Wine KD, Lockstadt H, Kovalsky D, Soo CL. Safety and 6-month effectiveness of minimally invasive sacroiliac joint fusion: A prospective study. Med Devices (Auckl) 2013; 6:219-229.

40. Sachs D, Capobianco R, Cher D, Holt T, Gundanna M, Graven T, Shamie N, Cummings JR. One-year outcomes after minimally invasive sacroiliac joint fusion with a series of triangular implants: Amulticenter, patient-level analysis. Med Devices (Auckl) 2014; 7:299-304.

41. Rudolf L, Capobianco R. Five-year clinical and radiographic outcomes after minimally invasive sacroiliac joint fusion using triangular implants. Open Orthop J 2014; 8:375-383.

42. Whang $P$, Cher D, Polly D, Frank C, Lockstadt H, Glaser J, Limoni R, Sembrano J. Sacroiliac joint fusion using triangular titanium implants vs. nonsurgical management: Six-month outcomes from a prospective randomized controlled trial. Int J Spine Surg 2015; 9:6.

43. Copay AG, Cher DJ. Is the Oswestry Disability Index a valid measure of response to sacroiliac joint treatment? Qual Life Res 2016; 25:283-292.

44. Duhon BS, Bitan F, Lockstadt $\mathrm{H}$, Kovalsky D, Cher D, Hillen T. triangular tita- nium implants for minimally invasive sacroiliac joint fusion: 2-year follow- up from a prospective multicenter trial. Int J Spine Surg 2016; 10:13.

45. Sturesson B, Kools D, Pflugmacher R, Gasbarrini A, Prestamburgo D, Dengler J. Six-month outcomes from a randomized controlled trial of minimally invasive $\mathrm{SI}$ joint fusion with triangular titanium implants vs conservative management. Eur Spine ] 2017; 26:708-719.

46. Polly DW, Swofford J, Whang PG, Frank C, Glauser J, Limoni R, Cher D, Wine K, Sembrano J. Two-year outcomes from a randomized controlled trial of minimally invasive sacroiliac joint fusion vs. nonsurgical management for sacroiliac joint dysfunction. Int J Spine Surg 2016; 10:28.

47. Halki J, Reiley M, Rudolf L, GrahamSmith A. Simplifying sacroiliac joint arthrodesis using MIS fusion implants. Spine ] 2010; 10: 553 .

48. Polly DW, Cher DJ, Wine KD, Frank C, Harvey C, Lockstadt H, Glaser J, Limoni R, Sembrano J. Randomized controlled trial of minimally invasive sacroiliac joint fusion using triangular titanium implants vs nonsurgical management for sacroiliac joint dysfunction: 12-month outcomes. Neurosurgery 2015; 77:674-69o.
49. Papanastassiou ID, Setzer M, Eleraky M, Baaj A, Nam T, Binitie O, Katsares K, Cheong D, Vrionis F. Minimally invasive sacroiliac fixation in oncologic patients with sacral insufficiency fractures using a fluoroscopy-based navigation system. J Spinal Disord Tech 2011; 24:76-82.

50. Kancherla VK, McGowan SM, Audley BN, Sokunbi G, Puccio ST. Patient reported outcomes from sacroiliac joint fusion. Asian Spine J 2017; 11:120-126.

51. Sachs D, Kovalsky D, Redmond A, Limoni R, Meyer SC, Harvey C, Kondrashov D. Durable intermediate-to long-term outcomes after minimally invasive transiliac sacroiliac joint fusion using triangular titanium implants. Med Devices (Auckl) 2016; 9:213-222.

52. Schünemann $H$, Brożek J, Guyatt $G$, Oxman A. GRADE Handbook. http://gdt. guidelinedevelopment.org/app/handbook/handbook.html. October 2013.

53. Schoell K, Buser Z, Jakoi A, Pham M, Patel NN, Hsieh PC, Liu JC, Wang JC. Postoperative complications in patients undergoing minimally invasive sacroiliac fusion. Spine ] 2016; 16:1324-1332.

54. Waisbrod H, Krainick JU, Gerbershagen HU. Sacroiliac joint arthrodesis for chronic lower back pain. Arch Orthop Trauma Surg 1987; 106:238-240. 